\title{
Characteristics of Reconstituted Collagen Fibers from Chicken Keel Cartilage Depends on Salt Type for Removal of Proteoglycans
}

\author{
Anna Pudło*D, Szymon Juchniewicz and Wiesław Kopeć (D)
}

Citation: Pudło, A.; Juchniewicz, S.; Kopeć, W. Characteristics of

Reconstituted Collagen Fibers from Chicken Keel Cartilage Depends on Salt Type for Removal of Proteoglycans. Molecules 2021, 26, 3538. https://doi.org/10.3390/ molecules26123538

Academic Editor: Heiko Lange

Received: 30 April 2021

Accepted: 8 June 2021

Published: 10 June 2021

Publisher's Note: MDPI stays neutral with regard to jurisdictional claims in published maps and institutional affiliations.

Copyright: (c) 2021 by the authors. Licensee MDPI, Basel, Switzerland. This article is an open access article distributed under the terms and conditions of the Creative Commons Attribution (CC BY) license (https:/ / creativecommons.org/licenses/by/ $4.0 /)$.
Department of Functional Food Products Development, Faculty of Biotechnology and Food Sciences, Wrocław University of Environmental and Life Sciences, 37 Chelmonskiego Str., 51-650 Wrocław, Poland; juchniewiczszymon@gmail.com (S.J.); wieslaw.kopec@upwr.edu.pl (W.K.)

* Correspondence: anna.pudlo@upwr.edu.pl

\begin{abstract}
The aim of the presented research was to obtain reconstituted atelocollagen fibers after extraction from poultry cartilage using the pepsin-acidic method in order to remove telopeptides from the tropocollagen. Firstly, we examined the extraction of collagen from the cartilage extracellular matrix (ECM) after proteoglycans (PG) had been removed by the action of salts, i.e., $\mathrm{NaCl}$ or chaotropic $\mathrm{MgCl}_{2}$. Additionally, the effects of the salt type used for PG and hyaluronic acid removal on the properties of self-assembled fibers in solutions at $\mathrm{pH} 7.4$ and freeze-dried matrices were investigated. The basic features of the obtained fibers were characterized, including thermal properties using scanning calorimetry, rheological properties using dynamic oscillatory rheometry, and the structure by scanning electron microscopy. The fibers obtained after PG removal with both analyzed types of salts had similar thermal denaturation characteristics. However, the fibers after PG removal with $\mathrm{NaCl}$, in contrast to those obtained after $\mathrm{MgCl}_{2}$ treatment, showed different rheological properties during gelatinization and smaller diameter size. Moreover, the degree of fibrillogenesis of collagens after $\mathrm{NaCl}$ treatment was complete compared to that with $\mathrm{MgCl}_{2}$, which was only partial $(70 \%)$. The structures of fibers after lyophilization were fundamentally different. The matrices obtained after $\mathrm{NaCl}$ pretreatment form regular scaffolds in contrast to the thin, surface structures of the cartilage matrix after proteoglycans removal using $\mathrm{MgCl}_{2}$.
\end{abstract}

Keywords: cartilage; collagen type II; reconstituted fibers; pepsin; proteoglycans

\section{Introduction}

Reconstituted collagen fibers (self-assembled after increasing the ionic strength or $\mathrm{pH}$ in monomer solutions) is the basis for creating matrices and scaffolding of biomaterials replacing soft or hard tissues, e.g., bones [1-5]. The main materials used for this purpose are reconstituted fibers of type I collagen obtained by the acid method or acid-enzymatic method with pepsin [6]. The latter is considered the most advantageous, as it removes telopeptides (the so-called atelocollagen is then formed), which reduces the immunogenicity of the obtained biomaterials that can be introduced into human tissues [7-9]. Among the many types of collagen, type II collagen is of particular interest, as it builds cartilage extracellular matrix (ECM) together with proteoglycans (PG) (mainly composed of sulfated glycosaminoglycans (GAG) linked to hyaluronic acid chain) [10]. Type II collagen is a raw material used in the production of dietary supplements; it is mainly made of by-products from the processing of fish cartilage. Another by-product that has been employed to some extent is poultry cartilage (keel) obtained from skeleton after muscle cutting. In addition to using collagen II as a dietary supplement (mainly as hydrolysate), reconstituted collagen II scaffolds are applied as biomaterial to replace cartilage [2-5]. Contrary to the well-known structure of reconstituted collagen fibers, mainly type I, collagen II fibers are less recognized. Hence, the basic thermal and rheological properties of reconstituted 
collagen II fibers are not well known. The procedure for the extraction and purification of collagen from cartilage, including the separation of the proteoglycan fraction, is of fundamental importance for the characteristics of these fibers. It is assumed that to obtain low immunogenicity of atelocollagen and high reconstitution capacity under conditions of increased ionic strength or $\mathrm{pH}$, the acid-pepsin procedure should be utilized, where two possible extraction methods can be employed. The first is direct degradation of the cartilage in acidic solution by pepsin, whereas the second involves initial separation of the proteoglycan fraction followed by collagen extraction. The first method produces atelocollagen extract high in proteoglycan contamination. In contrast, the second method provides cleaner collagen and facilitates the use of valuable proteoglycan fraction (mainly glycosaminoglycan chondroitin sulfate) for dietary supplements or the bioengineering of matrix components $[2,6]$.

Classic procedures usually involve the initial separation of proteoglycans, which is relatively easily achieved using buffered $\mathrm{NaCl}$ solution (so-called non-denaturing conditions) or chaotropic compounds, i.e., guanidine (most often a hydrochloride) or magnesium chloride $\left(\mathrm{MgCl}_{2}\right)$ on the $\mathrm{G} 1$ domain of the core protein and protein-linked proteoglycans to the chain of hyaluronic acid [11]. Such procedures enable the preservation of the collagen matrix of ECM in its entirety. Since guanidine cannot be used in food preparations (dietary or food supplements), it is advantageous to dissociate proteoglycans in $\mathrm{NaCl}$ or $\mathrm{MgCl}_{2}$ solution, as their possible residues do not preclude the use of proteoglycans in food. It is also beneficial in the extraction of collagen, as most procedures involve the precipitation of reconstituted collagen in saline solutions. Although the influence of non-denaturing conditions $(\mathrm{NaCl})$ or chaotropic salts $\left(\mathrm{MgCl}_{2}\right)$ on the dissociation of the proteoglycan fraction from the cartilage has been previously investigated, to the best of our knowledge, no data are available on the impact of these methods on the further course of isolation and structures obtained after the reconstitution of atelocollagen. Therefore, the aim of this study is to obtain reconstituted collagen II fibers from poultry cartilage using a method consisting of prior separation of proteoglycans as a result of the action of salts, i.e., $\mathrm{NaCl}$ or chaotropic $\mathrm{MgCl}_{2}$, which is followed by fiber structure characterization (also freeze-dried forms) as well as thermal and rheological features that are important for the formation of biomedical materials.

\section{Results and Discussion}

\subsection{Chemical Composition of the Raw Material}

The characteristics of cartilage indicate its suitability for obtaining purified forms of collagen useful in biomedical and food applications. The determined chemical composition of cartilage, i.e., dry matter, total protein, ash, collagen (hydroxyproline content), uronic acid, and glycosaminoglycans are presented in Table 1 . The obtained results show that $8.50 \%$ of total protein is in the raw material; however, Shin et al. [12] reported a value of approximately $11.8 \%$ of total protein, but it had an approximately $4 \%$ higher dry matter level than that in our research (i.e., $13.10 \%$ ). The differences result probably from the age of the chickens (very young 5-week-old broilers were studied, whereas in other studies, the age was over 7 weeks [13]). However, there is no difference in the share of ash per dry matter between our own and other studies [12,14]; this value is low and amounts to about $7 \%$, indicating that the cartilage is not mineralized. In fish and reptile cartilage tissues, the total protein level is higher than in poultry cartilage, ranging from $12 \%$ to $15 \%$, which is mainly due to the higher dry matter content of $25-45 \%[15,16]$. However, the proportion of proteins (collagen) and carbohydrates in dry matter in most of the raw materials was similar or lower than in chicken keel cartilage $(64.30 \%$ protein and almost $30 \%$ GAG in dry matter). 
Table 1. The chemical composition of the chicken keel cartilage.

\begin{tabular}{ccc}
\hline \multirow{2}{*}{ Parameters } & \multicolumn{2}{c}{ Concentration [\%] } \\
\cline { 2 - 3 } & Raw Tissue \pm SD & in Dry Matter \\
\hline dry matter & $13.10 \pm 0.81$ & 100.00 \\
protein & $8.50 \pm 0.26$ & 64.30 \\
ash & $0.90 \pm 0.10$ & 7.00 \\
fat & $0.09 \pm 0.02$ & 0.67 \\
hydroxyproline & $0.95 \pm 0.13$ & 7.25 \\
collagen & $7.19 \pm 0.98$ & 54.40 \\
uronic acid & $1.40 \pm 0.34$ & 10.70 \\
glycosaminoglycans & $3.80 \pm 0.42$ & 28.80 \\
\hline
\end{tabular}

Among collagen-rich poultry raw materials, chicken keel cartilage contains the highest amount of uronic acid. Nakano et al. [17] determined the value of $87.7 \mu \mathrm{g} / \mathrm{mg}$ dry weight for this raw material, while our own research showed an even higher level, i.e., $107 \mu \mathrm{g} / \mathrm{mg}$ dry weight (Table 1). Therefore, this raw material is potentially very valuable in terms of obtaining two main fractions, i.e., collagen and GAG. However, when generating pure forms of collagen, e.g., the reconstituted fibers, the necessity of removing large amounts of proteoglycans and their components, i.e., GAGs must be considered. One of the possibilities to remove GAGs is to use the chaotropic effect of salts; another is to use anion exchange column chromatography [18]. The purification and separation of collagen using column chromatography is also a long-established technique [19].

\subsection{PG Extraction from Cartilage (Pretreatment of Cartilage)}

The removal of proteoglycans from the cartilage during pretreatment in $\mathrm{NaCl}$ or $\mathrm{MgCl}_{2}$ salt solutions can be indicated through determination of the degree of their extraction from the chicken keel cartilage, which is expressed as the recovery of uronic acid and GAG in the solution in relation to the raw material (Table 2). The results show that $9 \mathrm{M}$ solutions of $\mathrm{MgCl}_{2}$ and buffered $\mathrm{NaCl}$ solution are equally effective in PG extraction from cartilage. The degree of proteoglycan extraction, especially after $48 \mathrm{~h}\left(23^{\circ} \mathrm{C}\right)$, is very high and accounted for over $97 \%$ of the total amount in the starting material.

Table 2. The extraction yield of uronic acid (UA) and glycosaminoglycans (GAG).

\begin{tabular}{ccccc}
\hline \multicolumn{2}{c}{ Extraction Conditions } & \multicolumn{2}{c}{ Yield [\%] } \\
\hline Type of Salt Solution & Time $[\mathrm{h}]$ & Temperature $\left[{ }^{\circ}\right.$ C] & UA & GAG \\
\hline $0.2 / 1.0 \mathrm{M} \mathrm{NaCl}$ & 24 & 4 & 97.3 & 98.5 \\
\hline \multirow{2}{*}{$3 \mathrm{M} \mathrm{MgCl}_{2}$} & 24 & \multirow{2}{*}{23} & 85.6 & 83.8 \\
& 48 & & 97.9 & 98.0 \\
\hline & $p$-Value & & 0.48 & 0.38 \\
\hline
\end{tabular}

\subsection{Extraction of Pepsin-Solubilized Collagen-Reconstituted Fibers}

After pretreatment of cartilage to remove PG, the precipitated collagen matrix was treated with pepsin ( $\mathrm{pH} 2.0$, citric acid). When $400 \mathrm{mg}$ of enzyme for $1 \mathrm{~g}$ of raw material was used, a practically complete dissolution of collagen was observed (95-97\% of hydroxyproline was found in solution), regardless of salt type used for pretreatment (Table 3). However, it should be emphasized that the amount of pepsin used in collagen extraction and raw materials rich in collagen was quite large, because for poultry or fish skins, smaller amounts of enzyme are to be used, e.g., about $100 \mathrm{mg} / \mathrm{g}[8,20,21]$. Additional enzyme $(300 \mathrm{mg} / \mathrm{g})$ was used in the process of collagen recovery from broiler legs [22], and for mineralized tissues such as bone elements, it was even over $1000 \mathrm{mg} / \mathrm{g}$ [23]. 
Table 3. Characteristics of the reconstituted and freeze-dried collagen fibers.

\begin{tabular}{cccr}
\hline $\begin{array}{c}\text { Type of Material after } \\
\text { Pretreatment }\end{array}$ & $\begin{array}{c}\text { Yield of Collagen Recovery } \\
\text { from Cartilage [\%] }\end{array}$ & $\begin{array}{c}\text { Recovery of Collagen in the } \\
\text { Form of Fibers [\%] }\end{array}$ & $\begin{array}{c}\text { Amount of Freeze-Dried } \\
\text { Collagen Fibers [mg/g Cartilage] }\end{array}$ \\
\hline $0.2 / 1.0 \mathrm{M} \mathrm{NaCl}$ & 95.1 & $95.2^{\mathrm{a}}$ & 120 \\
$3 \mathrm{M} \mathrm{MgCl}_{2}$ & 97.3 & $70.8^{\mathrm{b}}$ & 100 \\
\hline$p$-Value & 0.33 & 0.02 & 0.29 \\
\hline
\end{tabular}

Significant differences were found in the amount of obtained fibers depending on the method of proteoglycan removal (Table 3). The recovery of atelocollagen obtained in the form of reconstituted fibers from cartilage treated with NaCl-buffered solution (TRIS$\mathrm{HCl}$ ) reached approximately $95 \%$, which was higher than that of the raw material treated with $\mathrm{MgCl}_{2}$ solution (approximately 71\%). In reported studies, comparable high rates of collagen recovery from solutions (85-93\%) in the form of fibers after washing the cartilage with $\mathrm{NaCl}$ solution were observed. Other authors obtained similarly high results only for the fibrillogenesis of type I collagen from fish skins [24,25]. A greater degree of recovery of collagen fibers after $\mathrm{NaCl}$ pretreatment of cartilage also resulted in a greater mass of the lyophilized fiber matrix per raw material (Table 3).

\subsection{Differential Scanning Calorimetry (DSC)}

As shown in Table 4, DSC thermograms of cartilage and fibers display a single endothermic transition $\left(\mathrm{T}_{\mathrm{m}}\right)$, which is the unwinding of the triple helix of collagen [26]. Pretreatment using $\mathrm{NaCl}$ solution did not significantly change $\mathrm{T}_{\mathrm{m}}\left(65^{\circ} \mathrm{C}\right.$ vs. $64.5^{\circ} \mathrm{C}$ for raw cartilage), but the removal of $\mathrm{PG}$ fraction with $\mathrm{MgCl}_{2}$ slightly lowers $\left(62.5^{\circ} \mathrm{C}\right)$ collagen denaturation temperature in the residue. The $\mathrm{T}_{\mathrm{m}}$ of atelocollagen fibers obtained by the enzymatic-acid method (as a result of in vitro fibrillogenesis) was much lower than collagen in the cartilage (Table 4).

Table 4. Thermal characteristics of cartilage and collagen fibers determined by scanning calorimetry.

\begin{tabular}{lccc}
\hline \multicolumn{1}{c}{ Material } & $\mathbf{T}_{\mathbf{m}}\left[{ }^{\circ} \mathbf{C}\right]$ & $\begin{array}{c}\Delta \mathbf{H} \\
\text { [J/g Cartilage/Fibers] }\end{array}$ & $\begin{array}{c}\Delta \mathbf{H} \\
\text { [J/g Collagen] }\end{array}$ \\
\hline $\begin{array}{l}\text { Chicken keel cartilage } \\
\text { Cartilage residue after treatment }\end{array}$ & 64.5 & 0.5 & 7.1 \\
in $\mathrm{MgCl}_{2}$ solution & 62.5 & 1.8 & 17.7 \\
Cartilage residue after treatment & & & 23.3 \\
in NaCl solution & 65.0 & 2.1 & 118 \\
Collagen fibers $\mathrm{MgCl}_{2}$ (acidic) & 45.5 & 4.3 & 96.4 \\
Collagen fibers $\mathrm{NaCl}_{\text {(acidic) }}$ & 46.1 & 4.3 & 219 \\
Collagen fibers $\mathrm{MgCl}_{2}$, neutral pH & 55.9 & 5.1 & 156 \\
Collagen fibers $\mathrm{NaCl}_{\text {, neutral pH }}$ & 55.8 & 3.6 & \\
\hline
\end{tabular}

$\mathrm{T}_{\mathrm{m}}$-maximum transition temperature, $\Delta \mathrm{H}$ - total denaturation enthalpy.

Collagen fibers precipitated in acid solution were characterized by $\mathrm{T}_{\mathrm{m}}$ of $45.5^{\circ} \mathrm{C}$ and $46^{\circ} \mathrm{C}$, and a single transformation occurred in the thermograms in the temperature range $37-51{ }^{\circ} \mathrm{C}$ (Figure 1). The fibers obtained in neutral conditions by the dialysis of collagen solution against a phosphate buffer showed higher transformation temperatures $\mathrm{T}_{\mathrm{m}}$, which were close to $56^{\circ} \mathrm{C}$ (transition range 52-60 ${ }^{\circ} \mathrm{C}$ ) (Figure 2), thus indicating higher thermal resistance in contrast to that found for acidic fibers. The production of collagen neutral fibers with higher thermal stability is important, as it facilitates the drying or freeze-drying processes (higher temperatures treatment) as well as the use of atelocollagen fibers to create matrices for bioengineering applications [27]. 


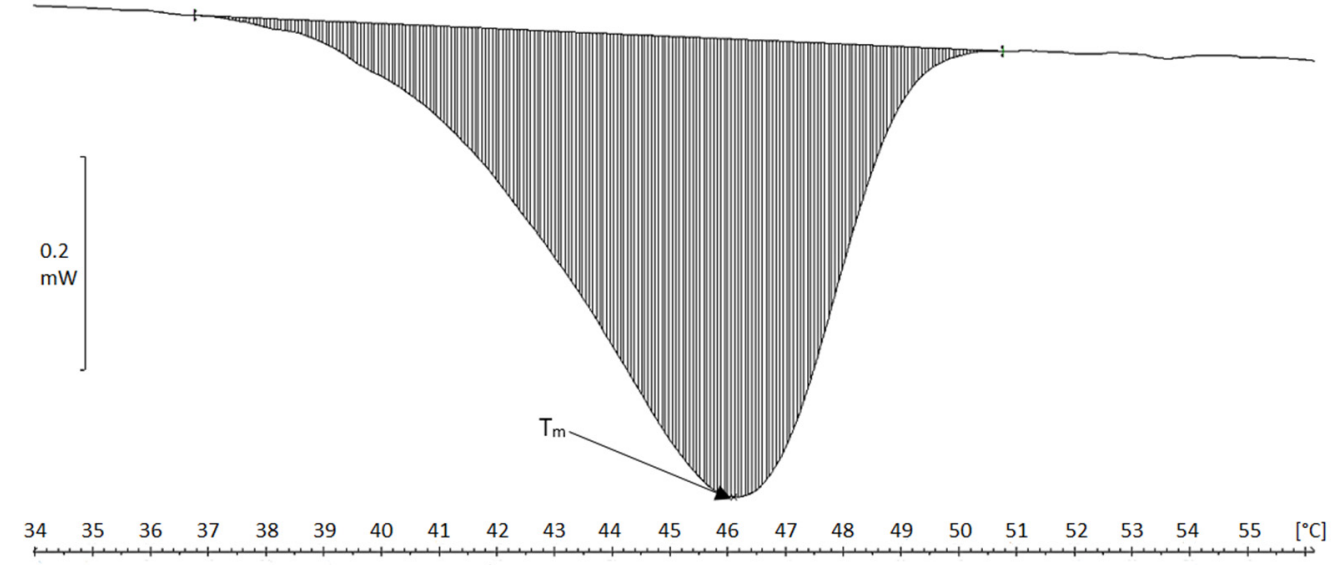

Figure 1. DSC thermogram of atelocollagen fibers in acid solution (obtained after pretreatment of the raw material in $\mathrm{NaCl}$ solution).

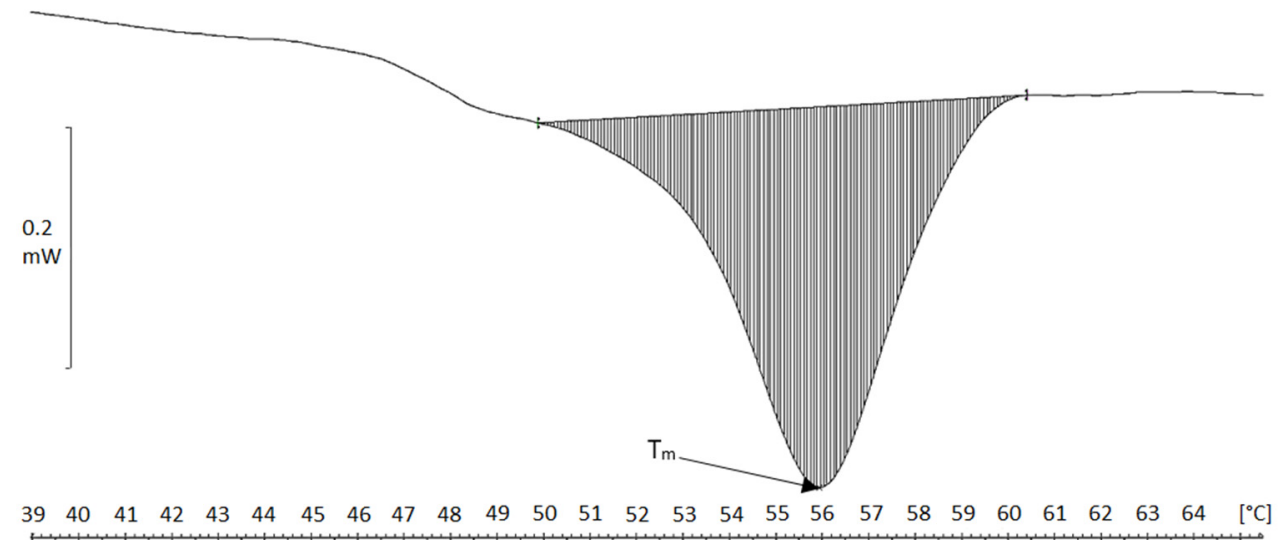

Figure 2. DSC thermogram of atelocollagen fibers in neutral solution (obtained after pretreatment of the raw material in $\mathrm{MgCl}_{2}$ solution).

There were significant differences in the value of enthalpy change between the raw material, i.e., cartilage, the residue after proteoglycan removal (i.e., mainly the collagen matrix of cartilage), and reconstituted collagen fibers (Table 4). If $\Delta \mathrm{H}$ is converted to the mass unit of collagen, then raw cartilage shows lower enthalpy than the residue after the removal of proteoglycans. However, the highest values were found for the reconstituted fibrils. Holmes et al. [28] showed that fibrillogenesis causes an increase in $\Delta \mathrm{H}$ value for atelocollagen fibers of approximately $20 \%$, and in our study, it was considerably higherby four times-compared to tropocollagen in cartilage and amounted to about $100 \mathrm{~J} / \mathrm{g}$. Even higher values were found for fibers after reconstitution in neutral solution $156 \mathrm{~J} / \mathrm{g}$ of collagen (after removal of PG in $\mathrm{NaCl}$ solution) and about $219 \mathrm{~J} / \mathrm{g}$ of collagen (after removal of PG in $\mathrm{MgCl}_{2}$ solution). This corresponds to the relationship given by Singh et al. [29], who indicated that under acidic conditions, collagen structure is destabilized due to cleavage of hydrogen bonds, which caused lowering both $\mathrm{T}_{\mathrm{m}}$ and enthalpy.

\subsection{Rheological Properties of Reconstituted Collagen}

Characteristics of phase transformations of reconstituted collagen fibers during heating and cooling were determined based on the storage modulus $G^{\prime}$ value (characterizing elastic properties of the material). The results showed that $\mathrm{G}^{\prime}$ was dependent on the type of raw material pretreatment (PG extraction). In the case of collagen after treatment in $\mathrm{NaCl}$ solution, during heating above $32{ }^{\circ} \mathrm{C}$, an increase in $\mathrm{G}^{\prime}$ value was observed (Figure 3). This transition, although dependent on temperature change, was similar to the aggregation of collagen microfibrils to create gel at temperatures of $32-37^{\circ} \mathrm{C}$, i.e., below the denaturation 
temperature according to Forgacs et al. [30] and Yang et al. [31]. An increase of elastic properties and $\mathrm{G}^{\prime}$ value may also be caused by significant inhomogeneity in the gel structure, consisting of different concentrations of collagen fibrils at temperatures below the denaturation temperature $\left(37^{\circ} \mathrm{C}\right)$ [32]. Our results showed an increase of $\mathrm{G}^{\prime}$ before unfolding the collagen molecules in the range $37-46^{\circ} \mathrm{C}$ (Figure 3). After that, at approximately $52{ }^{\circ} \mathrm{C}$, the main phase transition was observed, which involved thermohydrolysis (gelatinization) and a related reduction of $\mathrm{G}^{\prime}$ to very low levels. This transformation completed at $56^{\circ} \mathrm{C}$ (Figure 3).

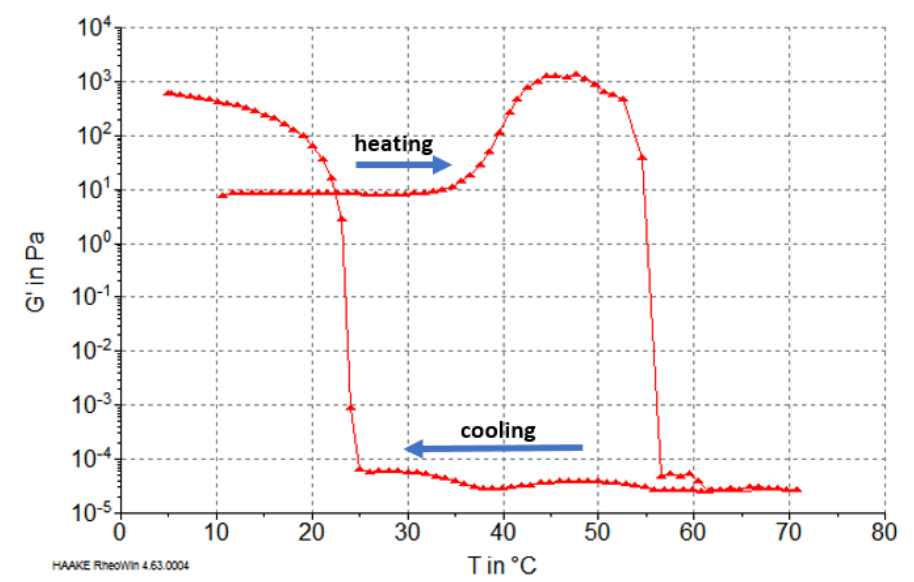

Figure 3. Changes in the $\mathrm{G}^{\prime}$ value of atelocollagen fibers (from cartilage after pretreatment with $\mathrm{NaCl}$ ).

During the cooling carried out after the heating phase, the collagen solution (actually gelatin) was gelled. This process began at approximately $25^{\circ} \mathrm{C}$ and ended at approximately $8^{\circ} \mathrm{C}$. For fibers obtained from cartilage after pretreatment with $\mathrm{MgCl}_{2}$ solution, no increase in $\mathrm{G}^{\prime}$ was observed at temperatures below $40^{\circ} \mathrm{C}$, and the decrease of $\mathrm{G}^{\prime}$ (gelatinization) occurred at temperatures ranging from 42 to $48^{\circ} \mathrm{C}$; i.e., it was lower than for fibers obtained after treatment with $\mathrm{NaCl}$ solution (Figure 4). Therefore, a lower heat resistance of the reconstituted collagen was obtained after PG removal from the cartilage with $\mathrm{MgCl}_{2}$.

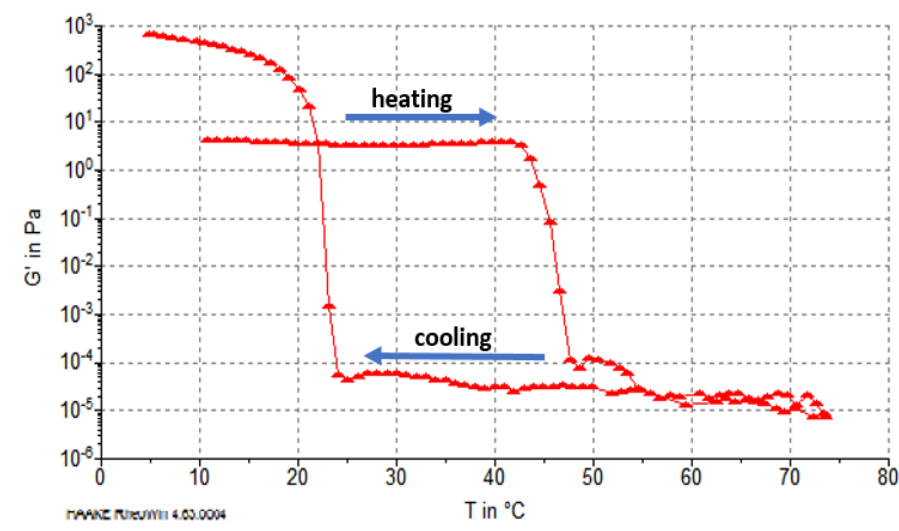

Figure 4. Changes in the $\mathrm{G}^{\prime}$ value of atelocollagen fibers (from cartilage after pretreatment with $\mathrm{MgCl}_{2}$ ).

However, it should be emphasized that the rheological characteristics of the gelatins of both types of collagen fibers (i.e., after heating to over $70^{\circ} \mathrm{C}$ and gelatinization) were similar, and the sol-gel transformation during cooling began at $25^{\circ} \mathrm{C}$. The final $\mathrm{G}^{\prime}$ value after cooling for both types of gelatin was higher than that of the starting collagen fibers, which was related to the partial recovery of the triple helix upon cooling of the gelatin solutions, as reported by Eysturskard et al. [33]. 


\subsection{Microstructure of Atelocollagen Fibers (Type II Collagen)}

Figure $5 \mathrm{~A}, \mathrm{~B}$ show the undulated, intertwined fibrous structures formed by the basic units, the sub-fibers. We observed a different degree of aggregation of sub-fibers with a diameter of $0.1-0.2 \mu \mathrm{m}(100-200 \mathrm{~nm})$. These aggregates formed locally, weakly bound collagen fiber bundles (2-3 sub-fibers each) with a diameter of approximately $450 \mathrm{~nm}$. The most contrasting were the SEM images of fibers obtained from collagen after PG removal with $\mathrm{NaCl}$ solutions. Upon extraction of PG from cartilage using $\mathrm{MgCl}_{2}$, the fiber structures were thicker and more blended (diameter 170-550 nm) (Figure 5B), or large fibrillar structures similar in size $(1.4-3.6 \mu \mathrm{m})$ to collagen fiber bundles (longitudinal structures) in cartilage were formed.

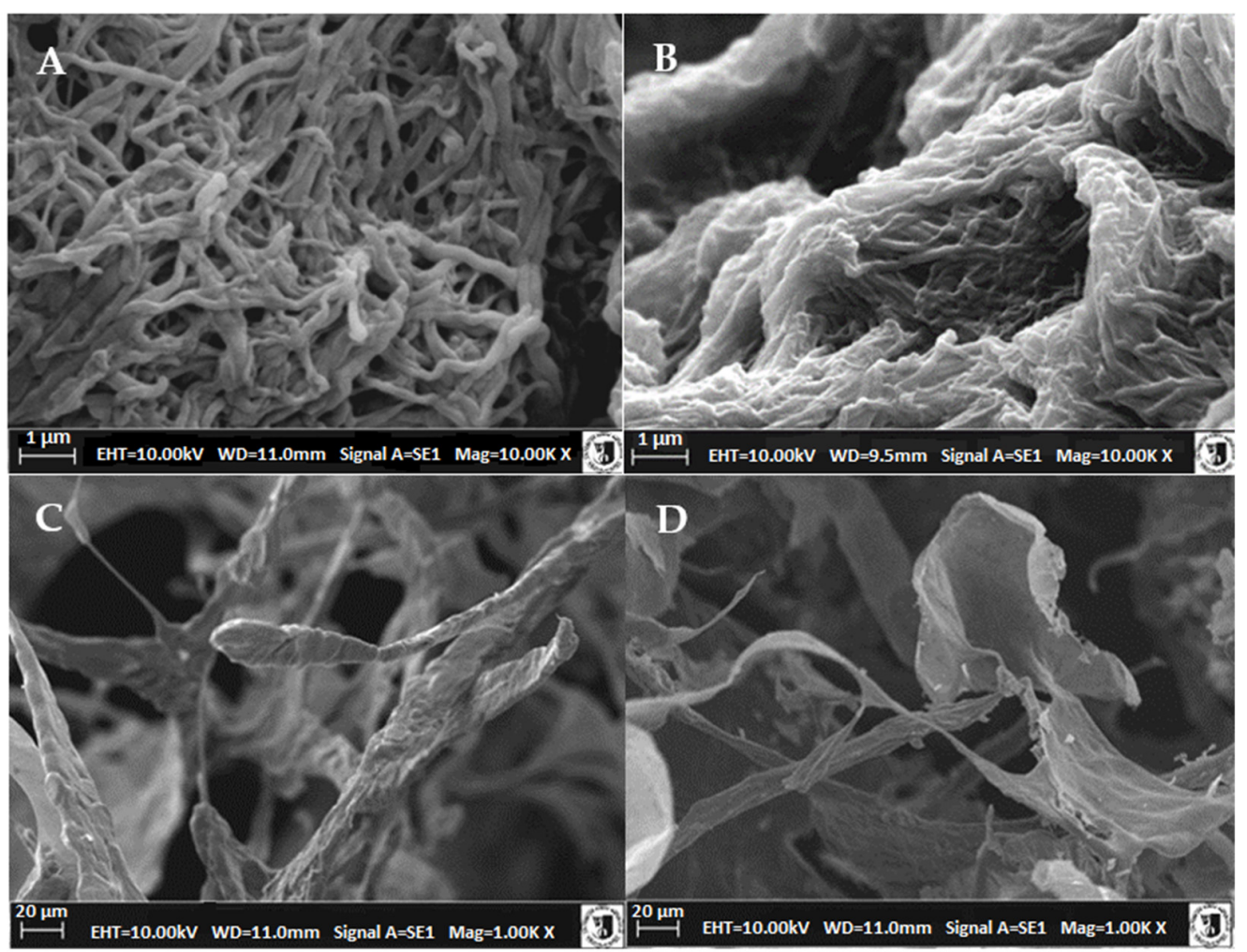

Figure 5. Electron microgram SEM of (A) reconstituted atelocollagen fibers (neutral solution at $\mathrm{pH}$ 7.4) isolated from chicken keel cartilage after preliminary proteoglycan extraction with $\mathrm{NaCl}$ solution; (B) isolated from chicken keel cartilage after extraction with $\mathrm{MgCl} 2$ solution; (C) freezedried preparations of reconstituted collagen fibers obtained in a neutral solution at $\mathrm{pH}$ 7.4; isolated from cartilage after preliminary extraction of proteoglycans with $\mathrm{NaCl}$ solution; (D) from cartilage after extraction of proteoglycans with $\mathrm{MgCl} 2$ solution.

Type I, II, and III collagens can undergo fibrillogenesis [34], but only the process of type I collagen reconstitution was described in detail, including its structure [35]. The concentration of atelocollagen as well as the $\mathrm{pH}$ and ionic strength of their representative solutions are essential for the morphology and size of secondary fibrils.

Filamentogenesis at low ionic strength and $\mathrm{pH} 7.0$ led to the formation of collagen type I bundles of 100-200 nm in diameter [36]. Similar conditions were employed in our study, where the ionic strength of the solution with $\mathrm{pH} 7.4$ was shaped only by $10 \mathrm{mM}$ phosphate buffer, and the obtained collagen II fibers (sub-fibers) were characterized with a diameter of 100-200 nm. Typical reconstituted fibers of collagen type I derived from slaughter materials (skin or mammalian tendons) separated in solutions with high ionic strength reached $250-300 \mathrm{~nm}$ in diameter $[37,38]$. When it comes to type II collagen fibers, there are little data on them in the literature. For example, fish cartilage was previously used to obtain fibers with a diameter of 50-100 $\mathrm{nm}$ [24], while that from bovine cartilage 
was used to obtain fibers with a diameter of 80-120 $\mathrm{nm}$ [37]. No images of the reconstituted fibers of collagen type II from poultry cartilages are available in the literature. However, the morphological data of the folded fibers obtained in our study were similar to that presented by Liang et al. [16] for collagen type II from sturgeon cartilage.

The lyophilization of atelocollagen fibers leads to the formation of porous structures (matrices) containing protein fibers with diameters from approximately 5 to $20 \mu \mathrm{m}$ with a partially preserved fiber structure (preparation after PG NaCl extraction) (Figure 5C) or thinwalled three-dimensional structures (preparation after PG $\mathrm{MgCl}_{2}$ extraction) (Figure 5D). These differences in structures obtained after lyophilization were unprecedented, as the thicker, more dense fibrils or filaments obtained from collagen after $\mathrm{MgCl}_{2}$ pretreatment gave thin, superficial structures resembling gelatin biomaterials. In contrast, the thinner fibers (after $\mathrm{NaCl}$ treatment) formed a very regular scaffold similar to those indicated by Pieper et al. [27], allowing the application of chondrocytes or structuring of surgical sponges.

The obtained ultrastructure images allow for interpretation of the previously discussed results. The thickness of the reconstituted collagen fibers obtained after $\mathrm{MgCl}_{2}$ pretreatment was considerably greater, and their dense structure indicated a different nature of the formed collagen fibers. This was due to variations in the initial procedures of removing proteoglycans from the cartilage. Of the two analyzed salts, $\mathrm{MgCl}_{2}$ showed a pronounced chaotropic effect that favors weaker water binding in the cartilage extracellular matrix after PG removal, which may alter the dissolution behavior of tropocollagen primary fibers. Although the efficiency of atelocollagen extraction from cartilage residue after PG removal in both salt solutions was comparable, the recovery of self-assembled collagen fibers was substantially different, i.e., higher for $\mathrm{NaCl}$ pretreated cartilage. This may be due to the extraction of larger collagen fragments from the cartilage residue or the higher degree of fiber/filament polymerization in solutions after $\mathrm{MgCl}_{2}$ pretreatment. For fibers pretreated with $\mathrm{NaCl}$, the degree of polymerization may be lower (as indicated by thinner fibers after fibrillogenesis). Although the efficiency of atelocollagen extraction from cartilage debris after PG removal in both salt solutions was similar, the recovery of self-assembled collagen fibers was substantially different; i.e., it was higher for $\mathrm{NaCl}$ pretreated cartilage and lower for $\mathrm{MgCl}_{2}$. These differences persist also after dialysis and influence the rheological behavior of the fibers. Namely, collagen with thin fibers clearly shows gelation before thermal denaturation, whereas thick fibers do not gel at temperatures below the main transformation. However, these variations were not significant enough to affect the thermal properties of dialyzed fibers, although thicker fibers had slightly higher enthalpy of main conversion (gelatinization). Furthermore, large differences were observed after freeze drying, which was a technique used for fixing collagen matrices intended for biomedical applications.

It should also be emphasized that the collagen preparations obtained in our research are not completely purified (e.g., GAG residues may reach $2-3 \%$-Table 2), which, as Stamov et al. [39] pointed out, may already affect the structure of collagen fibers. In addition, in the obtained collagen preparations that were characterized by a predominant content of type II, as indicated by the presence of only an $\alpha 1$ chain in the PAGE SDS pattern (Figure 6) (unlike the $\alpha 1$ and $\alpha 2$ chain bands for the collagen type I Sigma standard), it may be contaminated to a small extent with other types of collagen. This may affect the morphology of the reconstituted fibers, including creating FLS fibrous long spacing collagen forms [40], which is shown by banding with periodicity greater than that of native collagen. This can affect the properties of the obtained collagen preparations. 


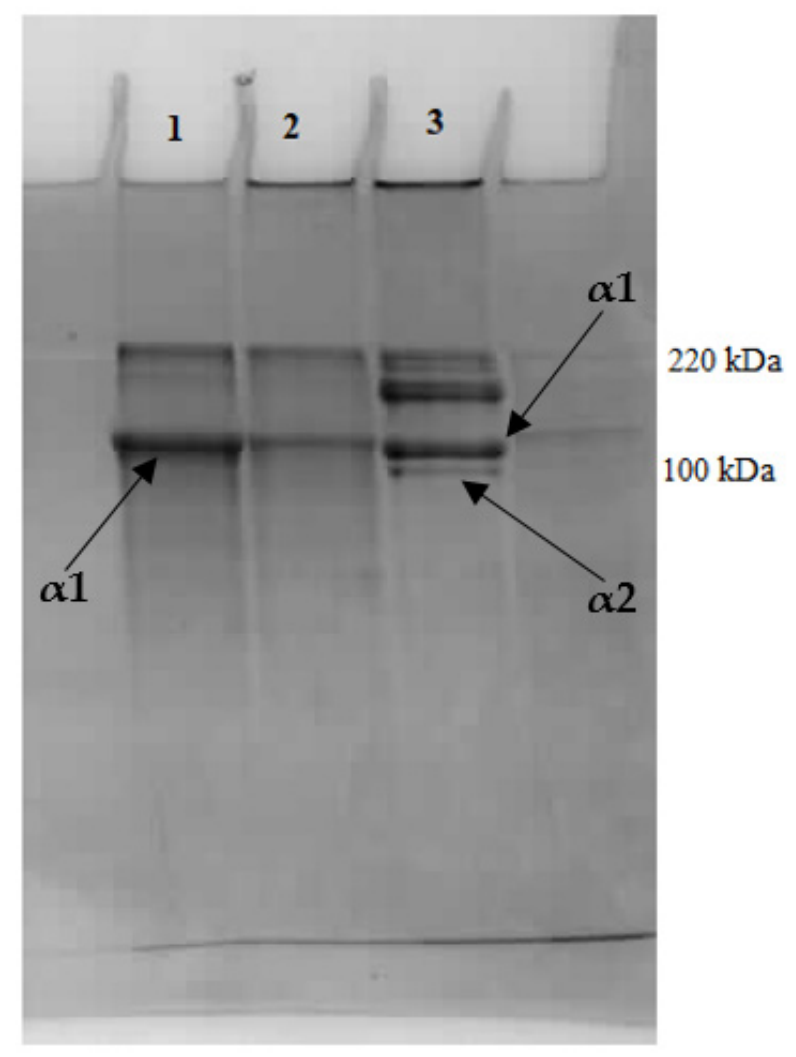

Figure 6. SDS-polyacrylamide gel electrophoresis of atelocollagen fibers isolated from chicken keel cartilage after preliminary proteoglycan extraction with (1) $\mathrm{MgCl}_{2}$ solution; (2) $\mathrm{NaCl}$ solution; (3) collagen type I (Sigma Aldrich).

\section{Materials and Methods}

\subsection{Materials}

The material used for this study was chicken keel cartilage, which was obtained from the broiler chicken carcass (5-week-old ROSS line), after cutting from the bony parts of the sternum. In young chickens, it is possible to obtain the sternum cartilage without bone contamination, both in the laboratory or even on an industrial scale. The cartilage was mechanically and hand cleaned from the remains of muscle tissue and was ground in a Retsch SM 2000 mill with a mesh diameter of 2 mm (Retsch, Haan, Germany); then, it was frozen and stored at $-20^{\circ} \mathrm{C}$ for no more than 2 months. Pepsin (400 units $/ \mathrm{mg}$ protein, Sigma Aldrich, Steinheim, Germany) from the gastric mucosa of pigs was applied.

\subsection{Extraction of Collagen Type II}

3.2.1. Pretreatment of the Raw Material (PG/GAG Extraction)

Proteoglycans were extracted from the raw material using the following solvents:

(a) $\quad 0.2 \mathrm{M}$ and 1.0 M NaCl solution in 0.05 M Tris-HCl buffer, $\mathrm{pH} 7.5,24 \mathrm{~h}, 1: 8(w / v), 4^{\circ} \mathrm{C}$ according to Cao and $\mathrm{Xu}[8]$,

(b) $3 \mathrm{M} \mathrm{MgCl}_{2}$ solution, pH 7.1, $24 \mathrm{~h}$, and $48 \mathrm{~h}, 1: 8(w / v), 23{ }^{\circ} \mathrm{C}$ [41].

The extract was separated by centrifugation at $15,000 \times g$, at $4{ }^{\circ} \mathrm{C}(15 \mathrm{~min})$. In the supernatant, the amount of hyaluronic acid and glycosaminoglycans was identified to determine the degree of PG extraction. The cartilage after pretreatment with $\mathrm{NaCl}$ or $\mathrm{MgCl}_{2}$ solution was analyzed for thermal properties using differential scanning calorimetry. Then, the precipitate of connective tissue was digested with pepsin to obtain atelocollagen type II. 


\subsubsection{Extraction of Pepsin-Solubilized Collagen}

The residue of cartilage containing the collagen fraction (after PG/GAG extraction) was washed 4 times with distilled water $(1: 9 w / v)$ to remove residues of salt solutions. Desalinated cartilage tissue was further treated enzymatically with pepsin in citric acid solution, $\mathrm{pH}$ 2.0. Extraction of collagen type II was performed with pepsin in the amount of $400 \mathrm{mg} / \mathrm{g}$ cartilage in citric acid solution at $\mathrm{pH} 2.0$. Incubation was carried out for $24 \mathrm{~h}$ in a water bath with stirring $(120 \mathrm{rpm})$ at $23^{\circ} \mathrm{C}$. The ratio of raw material to solution was $1: 10(w / v)$. After the end of the process, the samples were centrifuged $(15,000 \times g, 15 \mathrm{~min}$, $4{ }^{\circ} \mathrm{C}$ ). Then, the reconstitution of collagen fibers was carried out via precipitation (selfassembly) from the solution as a result of increasing the ionic strength. For this purpose, enough $\mathrm{NaCl}$ was added to the atelocollagen-containing supernatant to obtained $0.9 \mathrm{M}$ final salt concentration in solution, which was left for $16 \mathrm{~h}$ at $4{ }^{\circ} \mathrm{C}$. Then, the solutions containing the precipitated collagen fibers were centrifuged $\left(15,000 \times \mathrm{g}, 30 \mathrm{~min}, 4^{\circ} \mathrm{C}\right)$, and the resulting precipitate was analyzed as "acid fibers" or dialyzed (dialysis membrane with $12,000 \mathrm{Da}$ cut-off) against $0.01 \mathrm{M}$ phosphate buffer solution ( $\mathrm{pH} 7.4$ ) at $4{ }^{\circ} \mathrm{C}$ to obtain the "neutral" ( $\mathrm{pH}$ 7.4) form of collagen fibers [8]. Neutral collagen fibers were tested in wet form or lyophilized to create structures/scaffolds for biomaterials. The purity of type II collagen preparations was verified by SDS-PAGE electrophoresis conducted on $10 \%$ gel according to Laemmli [42] using as a standard Sigma Aldrich (Steinheim, Germany, C7661) type I collagen from rat tail.

\subsection{Proximate Compositions of Cartilage}

Raw materials were analyzed for dry matter, ash, fat, and protein by the standard methods AOAC (2005).

\subsection{Quantitative Determination of Collagen (Hydroxyproline) and Proteoglycans or Glycosaminoglycans (Hyaluronic Acid and Chondroitin Sulfate) Content}

Hydroxyproline (Hyp) was determined using the spectrophotometric method according to ISO 3496: 1994(E), and Hyp content was used to balance collagen yield in individual fractions. To determine the approximate collagen content in raw cartilage, the Hyp content was multiplied by 7.57 (the only indicator reported in the literature for poultry collagen [43]. Hyaluronic acid was determined based on the method reported by Bitter and Muir [44]. The samples were hydrolyzed with $0.025 \mathrm{M}$ sodium tetraborate $\left(\mathrm{Na}_{2}\left[\mathrm{~B}_{4} \mathrm{O}_{5}(\mathrm{OH})_{4}\right] \times 10 \mathrm{H}_{2} \mathrm{O}\right)$ in sulfuric acid $\left(100{ }^{\circ} \mathrm{C}, 10 \mathrm{~min}\right)$. Then, $0.125 \%$ solution of carbazole in absolute ethanol was added, and the samples incubated for $15 \mathrm{~min}$ in a water bath at $100^{\circ} \mathrm{C}$. The absorbance was measured at a wavelength of $530 \mathrm{~nm}$. Standard curve was prepared for D-(+)-glucuronic acid (concentration from 4 to $40 \mu \mathrm{g} / \mathrm{mL}$ ). Glycosaminoglycans were measured spectrometrically (at $525 \mathrm{~nm}$, color reaction with dimethylmethylene blue) according to method described by Farndale et al. [45] using papain for protein hydrolysis. A standard curve was prepared from chondroitin 4-sulfate.

\subsection{Differential Scanning Calorimetry (DSC)}

The thermal properties of cartilage and collagen were analyzed using a differential scanning calorimeter DSC821e (Mettler Toledo, Greifensee, Switzerland). Samples weighing 30-80 mg were placed in medium-pressure stainless steel crucibles ( $120 \mu \mathrm{L}$ capacity). Heating was carried out in the temperature range of 15 to $120^{\circ} \mathrm{C}$. The heating rate was $0.5^{\circ} \mathrm{C} / \mathrm{min}$. Nitrogen (N2 5.0) was used as the shield gas at a flow rate of $60 \mathrm{~mL} / \mathrm{min}$. The reference sample was an empty vessel (medium-pressure stainless steel crucible) with a mass similar to that of the vessel with the sample. The temperature of maximum transition $\mathrm{T}_{\mathrm{m}}$ (the minimum of the heat curve) was recorded from the thermogram, and total denaturation enthalpy $(\Delta \mathrm{H})$ was determined by measuring the area of the DSC thermogram and expressed in Joule per gram of cartilage, fibers, or collagen content $[\mathrm{J} / \mathrm{g}]$. 


\subsection{Rheological Properties of Reconstituted Collagen Fibers}

The rheological characteristics of $2 \%$ collagen fiber solutions in $0.01 \mathrm{M}$ phosphate buffer solution ( $\mathrm{pH} 7.4$ ) were tested during the heating cycle from 10 to $70{ }^{\circ} \mathrm{C}$ and then cooled from 70 to $4{ }^{\circ} \mathrm{C}$ at a rate of $1.0^{\circ} \mathrm{C} / \mathrm{min}$ using Haake RheoStress 6000 oscillating rheometer (Thermo Fisher Scientific, Waltham, MA, USA). Measurements were carried out in the plate-cone system $\left(\mathrm{C} 60 / 1^{\circ} \mathrm{TiL}\right)$ with a diameter of $35 \mathrm{~mm}$ and angle of $1^{\circ}$. Changes in rheological characteristics expressed as values of the storage modulus $\left(G^{\prime}\right)$ were tested at a frequency of $0.05 \mathrm{~Hz}$ and oscillating stress of $1.0 \mathrm{~Pa}$.

\subsection{Scanning Electron Microscopy (SEM)}

The microstructure of the analyzed samples was observed using a Tesla BS 300 scanning microscope (TESCAN, Brno, Czech Republic) at an accelerating voltage of $5 \mathrm{kV}$ and magnifications from $100 \times$ to $10,000 \times$. Initially, the neutral wet atelocollagen fibers were washed in tert-butyl alcohol to avoid artificial sticking according to the method described by Zhang et al. [25]. Then, reconstituted neutral fibers (prewashed) or their lyophilized preparations were fixed with $2.5 \%$ glutaraldehyde (GA) in $0.1 \mathrm{M}$ phosphate buffer ( $\mathrm{pH} 7.6)$. The next stage of dehydration was conducted using ethanol solutions of increasing concentration $(50 \%, 70 \%, 80 \%, 90 \%, 95 \%$, and $100 \%)$, drying at the critical point using $\mathrm{CO}_{2}$, and finally spraying the preparation with technical gold.

\subsection{Statistical Analysis}

In the experiments, three batches of cartilage were used, performing three independent extractions and collagen fibrillogenesis for one batch of raw material $(3 \times 3=9)$. Measurements are presented as means \pm standard deviation (SD). Statistical analysis was performed using the STATISTICA 13.3 (StatSoft, Tulsa, OK, USA). The results obtained were analyzed using one-way analysis of variance (ANOVA), and Duncan's multiple range test was applied to determine the statistically significant differences $(a, b, c, d)$. The tables summarize the mean values and probability ( $p$-value) relating to one experimental discriminant for the entire experiment.

\section{Conclusions}

The type of cartilage pretreatment with salt solutions of different chaotropic properties affects the characteristics of the reconstituted atelocollagen fibers and matrices. The removal of proteoglycans from cartilage with $\mathrm{MgCl}_{2}$ with strong chaotropic properties reduces the potential ability of atelocollagen self-assembly in solutions $(70 \%$ of the total amount of atelocollagen), and the resulting collagen fibers are thicker than those obtained from cartilage after PG removal with $\mathrm{NaCl}$. Thinner collagen fibers show phase transitions, which are analyzed as changes in rheological characteristics (including gelatinization) at higher temperatures and form regular scaffolds after freeze drying, in contrast to thin spatial structures obtained after freeze drying of collagen fibers obtained after pretreatment of cartilage in $\mathrm{MgCl}_{2}$ solution. The conducted research allows the recognition of the possibility of creating biomaterials from a new raw material, i.e., waste poultry cartilage, and it extends the knowledge about the structure and properties of reconstituted type II collagen, which has been so far produced only from bone skeletal elements of fish, pigs, and cattle. The obtained preliminary results allow us to plan further research related to various methods of forming biomaterials from the reconstituted poultry cartilage collagen, including the combination of type II collagen matrices with glycosaminoglycans. Special attention will be paid to the effect of small amounts of GAG, which can remain in the collagen preparations after the purification procedure or intentionally added to the matrices.

Author Contributions: Conceptualization, A.P. and W.K.; methodology, W.K., A.P., and S.J.; investigation, A.P., S.J.; data curation, W.K. and A.P.; writing-original draft preparation, W.K. and A.P.; writing-review and editing, W.K. and A.P.; visualization, A.P. and S.J.; funding acquisition, A.P. and W.K. All authors have read and agreed to the published version of the manuscript. 
Funding: The publication is financed under the Leading Research Groups support project from the subsidy increased for the period 2020-2025 in the amount of $2 \%$ of the subsidy referred to Art. 387 (3) of the Law of 20 July 2018 on Higher Education and Science, obtained in 2019.

Institutional Review Board Statement: Not applicable.

Informed Consent Statement: Not applicable.

Data Availability Statement: Data are available from the corresponding author.

Conflicts of Interest: The authors declare no conflict of interest.

Sample Availability: Samples are available from the authors.

\section{References}

1. Vázquez, J.A.; Rodríguez-Amado, I.; Montemayor, M.I.; Fraguas, J.; del Pilar González, M.; Murado, M.A. Chondroitin sulfate, hyaluronic acid and chitin/chitosan production using marine waste sources: Characteristics, applications and eco-friendly processes: A review. Mar. Drugs 2013, 11, 747-774. [CrossRef]

2. Lin, Y.C.; Tan, F.; Marra, K.G.; Jan, S.S.; Liu, D.C. Synthesis and characterization of collagen/hyaluronan/chitosan composite sponges for potential biomedical applications. Acta Biomater. 2009, 5, 2591-2600. [CrossRef] [PubMed]

3. Parenteau-Bareil, R.; Gauvin, R.; Berthod, F. Collagen-based biomaterials for tissue engineering applications. Materials 2010, 3, 1863-1887. [CrossRef]

4. Veeruraj, A.; Arumugam, M.; Ajithkumar, T.; Balasubramanian, T. Isolation and characterization of collagen from the outer skin of squid (Doryteuthis singhalensis). Food Hydrocolloids 2015, 43, 708-716. [CrossRef]

5. Veeruraj, A.; Arumugam, M.; Balasubramanian, T. Isolation and characterization of thermostable collagen from the marine eel-fish (Evenchelys macrura). Process Biochem. 2013, 48, 1592-1602. [CrossRef]

6. Chang, C.H.; Liu, H.C.; Lin, C.C.; Chou, C.H.; Lin, F.H. Gelatin-chondroitin-hyaluronan tri-copolymer scaffold for cartilage tissue engineering. Biomaterials 2003, 24, 4853-4858. [CrossRef]

7. Rigo, C.; Hartmann, D.J.; Bairati, A. Electrophoretic and immunochemical study of collagens from Sepia officinalis cartilage. Biochim. Biophys. Acta 2002, 1572, 77-84. [CrossRef]

8. Cao, H.; Xu, S.-Y. Purification and characterization of type II collagen from chick sternal cartilage. Food Chem. 2008, 108, 439-445. [CrossRef] [PubMed]

9. Wu, J.J.; Weis, M.A.; Kim, L.S.; Eyre, D.R. Type III collagen, a fibril network modifier in articular cartilage. J. Biol. Chem. 2010, 285, 18537-18544. [CrossRef]

10. Gandhi, N.S.; Mancera, R.L. The structure of glycosaminoglycans and their interactions with proteins. Chem. Biol. Drug Des. 2008, 72, 455-482. [CrossRef]

11. Wilson, R.; Diseberg, A.F.; Gordon, L.; Zivkovic, S.; Tatarczuch, L.; Mackie, E.J.; Gorman, J.J.; Bateman, J.F. Comprehensive profiling of cartilage extracellular matrix formation and maturation using sequential extraction and label-free quantitative proteomics. Mol. Cell. Proteom. 2010, 9, 1296-1313. [CrossRef] [PubMed]

12. Shin, S.C.; You, S.J.; An, B.K.; Kang, C.W. Study on extraction of mucopolysaccharide-protein containing chondroitin sulfate from chicken keel cartilage. Asian Australas. J. Anim. Sci. 2006, 19, 601-604. [CrossRef]

13. Shen, Q.; Zhang, C.; Jia, W.; Qin, X.; Cui, Z.; Mo, H.; Richel, A. Co-production of chondroitin sulfate and peptide from liquefied chicken sternal cartilage by hot-pressure. Carbohydr. Polym. 2019, 222, 1-10. [CrossRef] [PubMed]

14. Cordeiro, A.R.R.; Bezerra, T.K.A.; Queiroz, A.L.M.; Galvão, M.S.; Cavalcanti, M.T.; Pacheco, M.T.B.; Madruga, M.S. Collagen production from chicken keel bone using acid and enzymatic treatment at a temperature of $30{ }^{\circ} \mathrm{C}$. Food Sci. Technol. 2020, 40, 491-497. [CrossRef]

15. Garnjanagoonchorn, W.; Wongekalak, L.; Engkagul, A. Determination of chondroitin sulfate from different sources of cartilage. Chem. Eng. Process. 2007, 46, 465-471. [CrossRef]

16. Liang, Q.; Wang, L.; Sun, W.; Wang, Z.; Xu, J.; Ma, H. Isolation and characterization of collagen from the cartilage of Amur sturgeon (Acipenser schrenckii). Process Biochem. 2014, 49, 318-323. [CrossRef]

17. Nakano, T.; Pietrasik, Z.; Ozimek, L.; Betti, M. Extraction, isolation and analysis of chondroitin sulfate from broiler chicken biomass. Process Biochem. 2012, 47, 1909-1918. [CrossRef]

18. Silva, C.; Novoa-Carballal, R.; Reis, R.L.; Pashkuleva, I. Following the enzymatic digestion of chondroitin sulfate by a simple GPC analysis. Anal. Chim. Acta 2015, 885, 207-213. [CrossRef]

19. Kang, A.H.; Piez, K.A.; Gross, J. Characterization of the $\alpha$-chains of chick skin collagen and the nature of the amino-terminal cross-link region. Biochemistry 1969, 8, 3648-3655. [CrossRef]

20. Kittiphattanabawon, P.; Benjakul, S.; Visessanguan, W.; Shahidi, F. Isolation and characterization of collagen from the cartilages of brownbanded bamboo shark (Chiloscyllium punctatum) and blacktip shark (Carcharhinus limbatus). LWT Food Sci. Technol. 2010, 43, 792-800. [CrossRef] 
21. Matmaroh, K.; Benjakul, S.; Prodpran, T.; Encarnacion, A.B.; Kishimura, H. Characteristics of acid soluble collagen and pepsin soluble collagen from scale of spotted golden goatfish (Parupeneus heptacanthus). Food Chem. 2011, 129, 1179-1186. [CrossRef] [PubMed]

22. Lin, Y.K.; Liu, D.C. Effects of pepsin digestion at different temperatures and times on properties of telopeptide-poor collagen from bird feet. Food Chem. 2006, 94, 621-625. [CrossRef]

23. Liu, D.; Liang, L.; Regenstein, J.M.; Zhou, P. Extraction and characterisation of pepsin-solubilised collagen from fins, scales, skins, bones and swim bladders of bighead carp (Hypophthalmichthys nobilis). Food Chem. 2012, 133, 1441-1448. [CrossRef]

24. Yunoki, S.; Nagai, N.; Suzuki, T.; Munekata, M. Novel biomaterial from reinforced salmon collagen gel prepared by fibril formation and cross-linking. J. Biosci. Bioeng. 2004, 98, 40-47. [CrossRef]

25. Zhang, X.; Ookawa, M.; Tan, Y.; Ura, K.; Adachi, S.; Takagi, Y. Biochemical characterisation and assessment of fibril-forming ability of collagens extracted from Bester sturgeon Huso huso x Acipenser ruthenus. Food Chem. 2014, 160, 305-312. [CrossRef]

26. Wallace, D.G.; Condell, R.A.; Donovan, J.W.; Paivinen, A.; Rhee, W.M.; Wade, S.B. Multiple denaturational transitions in fibrillar collagen. Biopolymers 1986, 25, 1875-1893. [CrossRef]

27. Pieper, J.S.; van der Kraan, P.M.; Hafmans, T.; Kamp, J.; Buma, P.; van Susante, J.L.C.; van den Berg, W.B.; Veerkamp, J.H.; van Kuppevelt, T.H. Crosslinked type II collagen matrices: Preparation, characterization, and potential for cartilage engineering. Biomaterials 2002, 23, 3183-3192. [CrossRef]

28. Holmes, R.; Kirk, S.; Tronci, G.; Yang, X.; Wood, D. Influence of telopeptides on the structural and physical properties of polymeric and monomeric acid-soluble type I collagen. Mater. Sci. Eng. C 2017, 77, 823-827. [CrossRef] [PubMed]

29. Singh, P.; Benjakul, S.; Maqsood, S.; Kishimura, H. Isolation and characterisation of collagen extracted from the skin of striped catfish (Pangasianodon hypophthalmus). Food Chem. 2011, 124, 97-105. [CrossRef]

30. Forgacs, G.; Newman, S.A.; Hinner, B.; Maier, C.W.; Sackmann, E. Assembly of collagen matrices as a phase transition revealed by structural and rheologic studies. Biophys. J. Vol. 2003, 84, 1272-1280. [CrossRef]

31. Yang, Y.; Leone, L.M.; Kaufman, L.J. Elastic moduli of collagen gels can be predicted from two-dimensional confocal microscopy. Biophys. J. 2009, 97, 2051-2060. [CrossRef]

32. Latinovic, O.; Hough, L.A.; Ou-Yang, H.D. Structural and micromechanical characterization of type I collagen gels. J. Biomech 2010, 43, 500-505. [CrossRef]

33. Eysturskard, J.; Haug, I.J.; Elharfaoui, N.; Djabourov, M.; Draget, K.I. Structural and mechanical properties of fish gelatin as a function of extraction conditions. Food Hydrocoll. 2009, 23, 1702-1711. [CrossRef]

34. Birk, D.E.; Silver, F.H. Collagen fibrillogenesis in vitro: Comparison of types I, II, and III. Arch. Biochem. Biophys. 1984, 235, 178-185. [CrossRef]

35. Harris, R.; Reiber, A. Influence of saline and $\mathrm{pH}$ on collagen type I fibrillogenesis in vitro: Fibril polymorphism and colloidal gold labeling. Micron 2007, 38, 513-521. [CrossRef] [PubMed]

36. Harris, J.R.; Soliakov, A.; Lewis, R.J. In vitro fibrillogenesis of collagen type I in varying ionic and $\mathrm{pH}$ conditions. Micron 2013, 49, 60-68. [CrossRef]

37. Douglas, T.; Heinemann, S.; Bierbaum, S.; Scharnweber, D.; Worch, H. Fibrillogenesis of collagen types I, II, and III with small leucine-rich proteoglycans decorin and biglycan. Biomacromolecules 2006, 7, 2388-2393. [CrossRef] [PubMed]

38. Bae, I.; Osatomi, K.; Yoshida, A.; Yamaguchi, A.; Tachibana, K.; Oda, T.; Hara, K. Characteristics of a self-assembled fibrillar gel prepared from red stingray collagen. Fisheries Sci. 2009, 75, 765-770. [CrossRef]

39. Stamov, D.R.; Müller, A.; Wegrowski, Y.; Brezillon, S.; Franz, C.M. Quantitative analysis of type I collagen fibril regulation by lumican and decorin using AFM. J. Struct. Biol. 2013, 183, 394-403. [CrossRef] [PubMed]

40. Paige, M.F.; Rainey, J.K.; Goh, M.C. A study of fibrous long spacing collagen ultrastructure and assembly by atomic force microscopy. Micron 2001, 32, 341-353. [CrossRef]

41. Luo, X.M.; Fosmire, G.J.; Leach, R.M., Jr. Chicken keel cartilage as a source of chondroitin sulfate. Poultry Sci. 2002, 81, 1086-1089. [CrossRef] [PubMed]

42. Laemmli, U.K. Cleavage of Structural Proteins during the Assembly of the Head of Bacteriophage T4. Nature 1970, 227, 680-685. [CrossRef] [PubMed]

43. Cliché, S.; Amiot, J.; Avezard, C.; Gariépy, C. Extraction and characterization of collagen with or without telopeptides from chicken skin. Poultry Sci. 2003, 82, 503-509. [CrossRef] [PubMed]

44. Bitter, T.; Muir, H.M. A modified uronic acid carbazole reaction. Anal. Biochem. 1962, 4, 330-334. [CrossRef]

45. Farndale, W.R.; Buttle, D.J.; Barrett, A.J. Improved quantitation and discrimination of sulphated glycosaminoglycans by use of dimethylmethylene blue. Biochim. Biophys. Acta 1986, 883, 173-177. [CrossRef] 